\title{
Nanociência E Nanotecnologia no Ensino Médio: Potencialidades da Educação CTS
}

\author{
Edvaldo Vieira Faria Junior ${ }^{1}$, Roseline Beatriz Strieder ${ }^{2}$ \\ 1,2 Universidade de Brasília (UnB)
}

Palavras-Chave: Ensino de Física, Perspectiva CTS, Nanociência.

\section{Introdução}

A presente proposta pedagógica se inscreve na perspectiva CTS (Ciência, Tecnologia, Sociedade) ao considerar as implicações do desenvolvimento científico-tecnológico no contexto social, discutidas a partir da observação dos diversos problemas ambientais, políticos, culturais e econômicos causados pelo envolvimento global das novas tecnologias em nossa sociedade.

Nessa perspectiva e de acordo com Santos (2011), propomos a popularização da ciência por meio de uma Educação Científica que supera a simples divulgação da ciência e de suas aplicações, alocando-a no campo da participação popular.

Esses pressupostos direcionam pedagogicamente o presente trabalho ao contribuir para a conscientização e participação pública sobre as aplicações, o desenvolvimento, os riscos, os impactos, as incertezas e as políticas públicas em torno da Nanociência e da Nanotecnologia, visto que esses termos se complementam e são indissociáveis na medida em que a Nanociência é compreendida como o estudo das técnicas e aplicações das Nanotecnologias, contanto com o envolvimento de diversas áreas do conhecimento como as engenharias, a física, a química, a eletrônica, a computação e outras.

Entendemos, portanto, que é necessário estender nossos olhares para a relação entre a ciência, a tecnologia e a sociedade para que possamos promover a participação pública nesses assuntos. Nesse sentido, a educação CTS é capaz de potencializar a abordagem do tema Nanociência e Nanotecnologia pois, de acordo com Acevedo (1996), quando se associa a sociedade ao desenvolvimento científico-tecnológico é possível promovermos a alfabetização científica, a contextualização social da ciência, a melhora do pensamento crítico, a discussão de problemas e a tomada fundamentada de decisões.

Como referência metodologia de implementação no Ensino Médio, os pressupostos de Strieder (2012) apresenta a escola como aquela capaz de preparar os alunos para o enfrentamento de novos problemas e para definição de novos rumos para si mesmo e para a sociedade, de forma que se desenvolvam novas percepções, novos questionamentos e compromissos sociais.

\section{Metodologia e Material}

A metodologia e a aplicação dessa proposta ocorreram em sete encontros, conforme o quadro a seguir:

Quadro 1: Configuração dos encontros

\begin{tabular}{|c|c|l|}
\hline $1{ }^{\circ}$ encontro & $23 / 02 / 2018$ & $\begin{array}{l}\text { Levantamento das compreensões e dos conhecimentos prévios sobre } \\
\text { Nanociência e Nanotecnologia }\end{array}$ \\
\hline $2^{\circ}$ encontro & $09 / 03 / 2018$ & $\begin{array}{l}\text { Apresentação de discussão de dois vídeos, no qual um abordava os } \\
\text { benefícios o o outro promovia uma reflexão sobre os riscos e as } \\
\text { incertezas da nanotecnologia. }\end{array}$ \\
\hline $3^{\circ}$ encontro & $13 / 04 / 2018$ & $\begin{array}{l}\text { Palestra de um especialista sobre o contexto das pesquisas e as } \\
\text { políticas públicas. }\end{array}$ \\
\hline $4^{\circ}$ encontro & $20 / 04 / 2018$ & $\begin{array}{l}\text { Aula expositiva para a organização e sistematização dos conhecimentos } \\
\text { sobre aplicações, desenvolvimento, riscos, impactos e incertezas da } \\
\text { Nanociência e da Nanotecnologia. }\end{array}$ \\
\hline
\end{tabular}




\begin{tabular}{|c|c|l|}
\hline $5^{\circ}$ encontro & $26 / 04 / 2018$ & $\begin{array}{l}\text { Discussões para levantamento das questões mais relevantes, bem } \\
\text { como as estratégias para a socialização dos temas e definição dos } \\
\text { macros temas. }\end{array}$ \\
\hline $6^{\circ}$ encontro & $08 / 08 / 2018$ & $\begin{array}{l}\text { Socialização dos conhecimentos com a comunidade escolar por meio } \\
\text { da exposição e apresentação de banners. }\end{array}$ \\
\hline $7^{\circ}$ encontro & $24 / 08 / 2018$ & Aplicação do questionário final, confraternização e agradecimentos. \\
\hline
\end{tabular}

Fonte: Próprio autor

Os materiais e recursos didáticos que utilizamos foram slides Power Point, vídeos, banners, aula expositiva, debates e palestra.

\section{Resultados, Discussão e Conclusão}

Observamos que a presente proposta se apresenta como um interessante estímulo para a formação de cidadãos críticos, conscientes, responsáveis pelo desenvolvimento científico e tecnológico da sociedade.

Consideramos ainda que essa proposta pode auxiliar o professor de Física na promoção uma Cultura de Participação no contexto do Ensino Médio por meio do desenvolvimento de percepções, de questionamentos e de compromissos sociais.

Além disso, as ações apresentadas aqui podem contribuir para a capacitação dos alunos no enfrentamento de novos problemas, na definição de novos rumos para si próprios e na participação ativa dos problemas sociais.

Concluímos também que professor deve se assumir como mediador, o aluno se assumir como sujeito ativo diante dos novos questionamentos, os conteúdos devem ser abordados a partir de problematizações e a sala de aula deve se apresentar como um ambiente investigativo.

Em linhas gerais, apresentamos uma proposta pedagógica que apresente novos conhecimentos capazes de melhorar as abordagens de temas tecnológicos, como N\&N, no contexto do Ensino Médio, fazendo uso da perspectiva CTS.

\section{Referências}

ACEVEDO DÍAZ, J. A. La tecnología en las relaciones CTS: una aproximación al tema. Enseñanza delas Ciências, v.14, n. 1, p. 35-44, 1996.

FREIRE, P. Conscientização: teoria e prática da libertação: uma introdução ao pensamento de Paulo Freire. São Paulo: Cortez \& Moraes, 2006.

SANTOS, W. L. P. dos. Significados da educação científica com enfoque CTS. In CTS e educação científica: desafios, tendências e resultados de pesquisas. Brasília: Ed. UNB, 2011. STRIEDER, R. B. Abordagens CTS na educação científica no Brasil: sentidos e perspectivas. Tese de Doutorado: Universidade de São Paulo, São Paulo, 2012.

Caruso, F. e Oguri V. Física Moderna - Origens Clássicas e Fundamentos Quânticos. Rio de Janeiro: Campus, 2006.

$\mathrm{CAO}, \mathrm{G}$. Nanostructures e nanomaterials: synthesis, properties e applications. Londres: Imperial College Press, 2004.

SCHULZ, P. A. B. O que é nanociência e para que serve a nanotecnologia? Física na Escola, v. 6, 2005. 